\title{
The Internet of Education Things (IoET): A Social Sciences Approach for Students Academic Purposes
}

\author{
Erond L. Damanik \\ \{eronddamanik@unimed.ac.id.\} \\ Anthropology Department, Faculty of Social Sciences, Universitas Negeri Medan, Indonesia
}

\begin{abstract}
This article aims to discuss the contribution of the usage of the internet in the learning process for academic purposes in the Social Sciences at the Department of Anthropology, Universitas Negeri Medan. Data obtained through a questionnaire on 6 topics and 17 items of internet usage in semesters 6,7 and 8 namely 119 students. Data were analyzed with descriptive statistics and product-moment correlations. Theoretical references used are the Internet of Education Things, an explanation of the Internet of Things from an educational perspective. The study concludes that there is a significant relationship between IoET and student academic purposes. Every student utilizes Wireless Fidelity to access references, teaching materials, student assignments, and thesis writing. Email and internet searches are the most common internet uses. The internet creates a more personal learning experience but the tendency is used for the benefit of other internet activities rather than academic purposes.
\end{abstract}

Keywords: Internet, Education, Social Sciences, Academic Purposes

\section{Introduction}

Education has a close relationship with technology. In this case, technological tools help find and develop information to mediate methods and models of transformation into knowledge. Having a good tool becomes a new path for learning activities, processes, finding ideas and connecting them with contextual situations around them. Technology is a light for education policy. However, in its implications, it still raises criticisms such as the decline in educational standards, lack of empowerment of students, non-standard curriculum, even the decline of university institutions. These reasons trigger a debate in the role and place of technology in the learning process. Basically, technology not only refers to computing but expands the human body from a pen into a pair of glasses and then into a garment [1].

The internet marked the fourth industrial revolution (4IR) in the $21^{\text {st }}$ Century, digital technology. 4IR has an impact on human transformation, namely changes in the way of life, ways of working and interactions. Changes to these three aspects are interrelated. The keywords of digital technology are interconnection and virtualization [2]. The internet changed the real world into a virtual one. The internet is a prerequisite for interconnection between the real world and the virtual world. The internet erases distances between countries around the world. The internet 
creates interconnections wherever and whenever. The internet is changing the use of computers and smartphones with a very broad reach. In other words, the breakthrough of 4IR in the $21^{\text {st }}$ Century is the presence of internet-based digital technology for all aspects of human life.

The internet includes two main benefits namely communication and information [3]. The 4IR today is characterized by innovative technology and the internet is the most prominent innovation in the modern revolution [4]. The 4IR is an emerging technology breakthrough in various areas such as the Internet of Things [2]. This technology not only contributes greatly to economic life [5], consumers, producers, and companies [6] but also in the educational and scientific fields [5], [7]. In the 21st Century, Higher Education must adapt to the development of this technology to produce graduates who have competitiveness [8]. In the 4IR era, tertiary education must move from stable infrastructure to fluid infrastructure.

The impact of 4IR on education in the $21^{\text {st }}$ Century gave rise to the Internet of Things (IoT) [1], [5], [6], [9]-[13]. IoT is the widespread use of internet connectivity in education. Both educators and students have an attachment to the internet about "all things" in the learning process. In this case, technology plays a role in making educators and students interact with the knowledge to create new knowledge [11]. Internet support in the 4IR era became the new culture of learning [14] namely obtaining information and knowledge not only in the classroom but from various sources and wherever located. In other words, information and communication technology (ICTs) in the 21st Century is connecting anytime, anyplace and anyone about anything [15].

The term IoT first appeared in 1999 which was coined by two MIT scholars who worked at Labs Auto-D centers namely Neil Gershenfeld and Kevin Ashton [16]. The basic idea of IoT is various objects such as Radio Frequency Identification (RFID), sensors and actuators that enable interaction with each other [17]. Computer and internet devices allow the processing of large amounts of data [18]. The support of information and data available on computers and the internet causes humans to depend on this modern technology. However, humans have limited time and accuracy that requires technology about various things from the real world. The internet allows getting very extensive information. The data is obtained online and developed through processing for effective decision making.

IoT is a technological revolution that represents the future of computing and communication. According to the Global Standards Initiative on the Internet of Things (IoT-GSI), IoT is a global infrastructure for the information community to facilitate the interconnection of all types of physical and virtual objects based on protocols and communication technology [15]. Then, the Internet Society mentions that IoT is network connectivity and computing capabilities including devices, objects, and sensors to produce, send or receive, or exchange data without human intervention [19]. Through IoT, each object can be controlled remotely via the internet so that it can be detected by a hardware system and able to interact in the internetworking landscape [20]. The development of this technology is highly dependent on the dynamics of technological innovations that occur in the field of wireless sensors to nanotechnology [6].

Internet devices are computers, cell phones, laptops, tablets, phablets or all types of devices that can receive IP addresses. All of this can be connected to other smart devices to collect and transfer data and make decisions [21], [22]. In this case, the concept of 'things' which has an important meaning. This word means an object or something that is considered to exist. Therefore, IoT is intended to: (1) every device, object, and item connected to the network, and (2) to involve real objects outside the computer. IoT provides information choices in all areas of life [18]. All 
data available on the internet is information that is calculated for each specific consequence and impact. This reality is the reason for the development of the system to help data processing while closing emotions to realize a scientific rational approach. Humans are disabled so that the process of data entry on the machine becomes defective [18]. However, machines have the advantage of capturing objective information about the real world and exploiting that potential to make better decisions. Therefore, computer devices need to be empowered in their way to gather information so that they can see, hear and smell the world for themselves randomly [18].

The scope of the application of IoT has a wide impact on human life such as smart cities, online businesses, smart homes, smart environments, security and emergencies, transportation, smart energy consumption, industrial processes, healthcare systems, monitoring and also education. In reality, IoT has a macro effect on human activities and objects. Education has become one of the most visible macro activities of human life. Communication technology becomes the most essential component for creating new models in education. The contribution of this technology to education is to change the knowledge transfer model that is collaborative, active, self-managed and increases knowledge into skills relevant to the digital learning society [23]. In the education room, IoT is a cloud technology and virtualization device that provides resources in the form of a big Database. This Big Database is connected with several institutions from all over the world and provides an opportunity for researchers to mark accurate predictive topics and sensibility analysis.

The use of the internet in tertiary institutions creates a new IoT format namely the Internet of Education Things (IoET). As an assumption, IoET is a reference and learning reference for many things for students and lecturers in universities. IoET functions for a variety of things namely: (1) storehouse of information, (2) communication without boundaries, (3) online interactive learning, (4) online research, (5) innovation in the new world, ( 6) improve interest in learning, (7) global education, and (viii) information catalogs [24]. Referring to the IoET function in this tertiary institution, IoET's contribution to the learning process is: (1) engagement in the learning process, (2) creativity, (3) e-learning, (4) self-learning, (5) research opportunity, (6) collaboration, (7) hyper-connectivity, and (8) and others such as scalability, education object performance (student and teacher), cognitive aspects, learning efficiency and Big Data [24]. IoT is not only beneficial for students and educators but also administration. Figure 1 below summarizes the benefits of IoT in the education process.
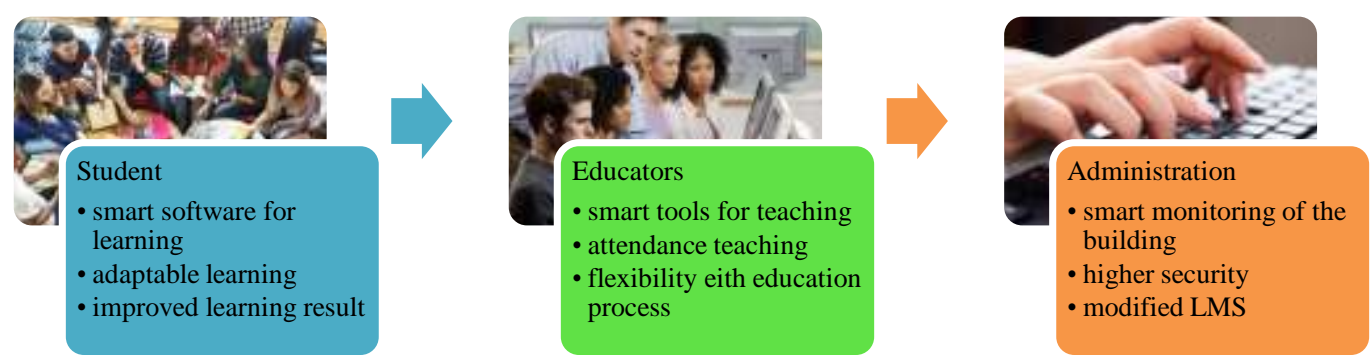

Fig. 1. Advantages of IoT for the education process 
This study discusses IoET for academic goals in Social Sciences in Indonesia. In this case, the strength of IoET in Social Sciences is access to multimodal learning resources. The strength of Social Sciences is the ability to understand social problems based on references, textbooks, working papers, journal articles, video analysis, dictionaries, web-based, thesis, thesis or dissertation. In line with the development of 4IR, all of these resources can be accessed online via the internet. The question is how intensely are students and lecturers accessing these learning resources and discussing them in class to solve social problems in Indonesia. This question becomes important considering that information and data via the internet are available in large quantities. Although the availability of information and data is very supportive of digital literacy, digital fluency of literacy skills is needed so that it does not produce bias.

Observations during 2017-2018 show that the internet is not only positive and bad for the Indonesian people. The threat of disintegration, polarization, radicalism, and fundamentalism based on primordial, poverty, injustice and others are things that need to be watched in Indonesia. Besides, 4IR makes it easy for anyone to write anything or make videos, sermons, and memes via the internet. Often, blogs or personal channels are used as references and are considered real truths without source criticism, theoretical debate or paradigm debate being used. Besides, videos about poverty, anarchist demonstrations, riots, looting, murder, traffic jams, rape, etc. are easily uploaded to the Internet and distributed via the web, social media or conversation groups. Some of the narratives are hoaxes or fakes which are deliberately exhaled as expressions of hatred. Facts in Indonesia show that for almost 1 decade of 4IR in political life in Indonesia, not a few had to deal with the police and in prison. Limitations and errors in finding material on the Internet have an impact on the analysis errors for the problems of the Indonesian people. It is important to underline that the social fabric of Indonesian society is plural and multicultural.

The Social Sciences has the responsibility for the sustainability of the community, namely the Republic of Indonesia. Therefore, digital literacy and digital fluency are urgently needed in Social Sciences to answer the social challenges of the 4IR era in Indonesia. It is time for this modern technological revolution to be used extensively for the development of knowledge and solving social problems in society. This study is intended to determine the contribution of IoET to academic goals in Social Sciences in Indonesia. In this study, IoET is placed as an independent variable $(\mathrm{X})$ and academic purposes as a dependent variable $(\mathrm{Y})$. The hypothesis proposed in this study is: IoET's contribution to the learning process has a positive and significant impact on student academic purposes. In a sense, a good mastery of IoET contributes greatly to student academic purposes.

Specifically, this study aims to: (1) identify the benefits of IoET for the learning process of students in Social Sciences, (2) find out the activeness and intensity of students interacting with the internet (looking for references, teaching materials and student assignments), (3) knowing internet content the most common among students, (4) identifying IoET risks to single-interface, app-based interfaces and the overall IoET ecosystem in the classroom, (5) knowing the practical and theoretical needs of social science based on digital literacy, and (6) find recommendations and guidance on strategies for implementing IoET for education policy in Indonesia. This study was conducted qualitatively with statistical methods as a supplementary supplement. A theoretical analysis of the IoET model especially on social sciences for academic purposes and their components will be outlined in the following. 


\section{Research methods}

The research method used is correlational. The research sample consisted of 119 people, namely all students who were registered and active in the Anthropology Department, Medan State University. The determination of the sample is based on considerations of the campus life experience, the use of more advanced computers and the internet, more contextual teaching material and thesis writing. This study was conducted in February-July 2019. In this study, IoET is the independent variable (X) and student academic purposes are the dependent variable (Y). Data variables $\mathrm{X}$ and $\mathrm{Y}$ were obtained by distributing questionnaires to respondents. The questionnaire focused on 6 topics and 17 items of internet use in the learning process. The questionnaire consists of 3 sections namely the general section includes 4 items, the core section includes 17 items of internet use in the learning process and section 3 are others.

Table1. Topics and items of internet use in the learning process

\begin{tabular}{|c|c|}
\hline Topics & Items \\
\hline - General & $\begin{array}{l}\text { - Internet usage behavior in the learning process } \\
\text { - Duration of internet usage on campus and home (hours per day) } \\
\text { - Internet contribution in the learning process } \\
\text { - Internet devices owned by students }\end{array}$ \\
\hline $\begin{array}{l}\text { - Search data by index and } \\
\text { addresses for the learning } \\
\text { process }\end{array}$ & $\begin{array}{l}\text { - Internet search engine for Social Sciences teaching material } \\
\text { - Access e-dictionary } \\
\text { - Access to internet-based information, news, and innovations }\end{array}$ \\
\hline $\begin{array}{l}\text { - e-Mail for the learning } \\
\text { process }\end{array}$ & - Correspondence and delivery of student task \\
\hline $\begin{array}{l}\text { Official web browsing for } \\
\text { the learning process }\end{array}$ & $\begin{array}{l}\text { - Read and write academic papers from different official websites } \\
\text { - In-depth review of internet-based teaching material topics } \\
\text { - Access the website of government agencies and universities } \\
\text { - Access the website of private agencies related to teaching materials }\end{array}$ \\
\hline $\begin{array}{l}\text { - Designing web-based } \\
\text { course. }\end{array}$ & $\begin{array}{l}\text { - Upload scripts, videos, photos, and images on blogs and make } \\
\text { comments }\end{array}$ \\
\hline $\begin{array}{l}\text { - Attending a course in using } \\
\text { the internet and its } \\
\text { application in education }\end{array}$ & $\begin{array}{l}\text { - Read or download photos and images for student assignments } \\
\text { - Read or download or watch videos relevant to teaching materials } \\
\text { - Read or download e-books, e-journals, working papers for } \\
\text { Assignments and thesis } \\
\text { - Translate English references with internet devices } \\
\text { - Read sources from various languages } \\
\text { - Share data via the internet } \\
\text { - Access e-learning system }\end{array}$ \\
\hline $\begin{array}{l}\text { - Social media for } \\
\text { educational communication }\end{array}$ & $\begin{array}{l}\text { - Interconnection through messenger, MSN, Facebook, Twitter and } \\
\text { WhatApps for academic and homework purposes }\end{array}$ \\
\hline - Other usages & $\begin{array}{l}\text { - e-Games, e-Cinema, e-Music and Song, e-Gambling, e-Commerce } \\
\text { (online shop), social media, etc. }\end{array}$ \\
\hline
\end{tabular}


Before analyzing data and testing hypotheses, instrument testing is first performed including the validity and reliability of the instrument. The validity test uses Product Moment from Pearson while the reliability test uses the Alpha Cronbach formula [25]. The data are analyzed by descriptive and correlational statistical methods. Data analysis was carried out through two steps namely normality and variable linearity tests. The normality test uses the Kolmogorov-Smirnov formula [26]. If the calculated results for each variable are greater than 0.052 -tailed significance the variable is normal. Linearity using the $\mathrm{F}_{\text {Test }}$. If the test results are greater than 0.05 then both variables are linear. Last is hypothesis testing. The tests are using the Pearson Product Moment correlation formula and Bivariate analysis [27]. If the $r_{\text {count }}$ value is greater than the $r_{\text {table }}$ value at the 0.05 significance level, then there is a significant correlation and vice versa, if the $r_{\text {count }}$ value is smaller than the $\mathrm{r}_{\text {table }}$ value at the 0.05 significance level then the two variables do not have a significant correlation.

\section{Result and discussion}

This section describes the results of the research in the form of instrument testing, data analysis, and hypothesis testing. The results of the instrument validity test produced 17 questions. Instrument reliability test results using Alpha Cronbach obtained 0, 830 which means very strong. Then, the normality test data obtained significance values of variables X and Y are 0,197 and 0.115 . This result concludes that both variables are normal. The data linearity test obtained by $F_{\text {count }}$ is 1,063 while the value of $F_{\text {table }}$ is 4.78 . These results indicate that the two variables are linear. Furthermore, the distribution of IoET questionnaires to 119 respondents obtained scores between 95-38, mean 75.19, median values 75, 29, mode values 74, 12 and standard deviation values 13.33. The length of the interval using the formula $K=1+3.3 \operatorname{LogN}$ is 8 .

This calculation illustrates IoET's contribution to the learning process as follows: $69.75 \%$ contributed very well, $26.05 \%$ contributed well, $3.36 \%$ contributed low and $0.84 \%$ contributed very low. This result concluded that IoET's contribution to the learning process was very good. Distribution of student academic purposes questionnaire obtained a score between 88-49, Mean 67, 90, 63.50 mode value, 63.50 Median value, and the standard deviation was 13.33 . The length of the interval using the formula $\mathrm{K}=1+3.3 \operatorname{LogN}$ is 8 . These results illustrate the tendency of student academic purposes at Medan State University namely: 11, $76 \%$ is very high, $73.10 \%$ is high, $14.28 \%$ is low and $0,38 \%$ is very low. This result concluded that student academic purposes were high.

Hypothesis testing uses the Product Moment correlation from Pearson. The correlation test of the two variables resulted in a $r_{\text {count }}$ of 0,348 and the correlation coefficient was 0,121 . This test mentioned that the correlation of IoET with student academic purposes was $12.1 \%$. The calculated value was consulted with $r_{\text {table }}$ at a significance level of 0.05 and obtained 0.176 . These results conclude that there is a significant and positive correlation between IoET and student academic purposes. Therefore, this study concludes that there is a positive contribution between IoET in the learning process towards student academic purposes. These findings indicate that the better the mastery of IoET in the learning process will have an impact on the higher the value of student 
academic purposes obtained by students. Conversely, the worse the mastery of IoET in the learning process has an impact on low student academic purposes.

As in other countries, the Internet for campuses in Indonesia has become a necessity for at least the past decade. Research data, dedication, lecturer data, student data, curriculum, and others have been connected to the internet. Campuses in Indonesia have adopted blended learning, a combination of offline and online learning. Material or material is not presented through words (powerpoint) alone but has used video streaming or video tutorials. Learning instructions, student assignments, the guidance of proposals and thesis, evaluation and monitoring are done online. The lecturer conveyed multimodal learning resources such as e-books, e-journals, official websites and others that can be accessed by students anytime and anywhere. Each student can access learning resources, read them and discuss them in class with other students who are mentored by educators. Besides, the learning paradigm in Indonesia has been adapted to 4IR which demands global competence and skills based on literacy, numeracy, and digital fluency. The two main components namely digital literacy and digital fluency are directed at the widest use of technology and the internet for educational purposes.

The below shows a general description of the results of the distribution of questionnaires to 119 respondents. Figure 2 below shows the data on internet usage behavior in the learning process. The tendency of student behavior to use the internet in the learning process on campus and at home is moderate (51.26\%). The highest internet usage behavior is only $35.29 \%$ and the rest $(13.44 \%)$ is low. This data shows that internet usage among students is on a moderate and low scale which is $64.73 \%$. The cause of the low use of the internet among students is caused by two things: firstly the introduction of the internet in the learning process is still relatively new, and secondly the lack of lecturers using the internet as a medium of instruction and accessing references, teaching materials and also student assignments. At Universitas Negeri Medan for example, blended learning, a model that combines offline and online learning, has only been applied since 2018. Then, only 3 lecturers have carried out instructions and collected student assignments and consultations on the preparation of the internet-based thesis (e-mail). This fact causes students to not make the internet as a need and habit in supporting the learning process.

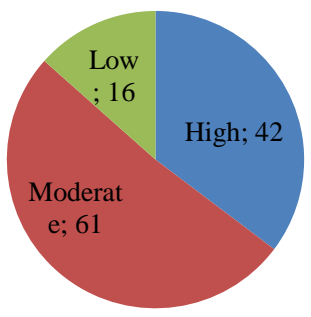

Fig. 2. Internet usage behavior in the learning process 
Table 2 below shows the duration of students using the internet in the learning process on campus and at home which is calculated based on the number of hours per day. Internet usage on campus less than 2 hours per day is $17.64 \%, 45.37 \%$ stated that they access the internet on campus for 2-3 hours per day, $31.93 \%$ stated that they access the internet for 3-4 hours per day, and only $5.04 \%$ stated that they access the internet for more than 4 hours per day. These results indicate that the average student accessing campus internet for 2-4 hours per day is $77.30 \%$. Internet usage for 2-4 hours per day on campus is the availability of Wireless Fidelity (WiFI). This fact helps the growth of digital culture even though the number of people accessing the internet for more than 4 hours is still very low.

The data in Table 2 presents internet usage at home. $74.78 \%$ access the internet less than 2 hours per day, $13.44 \%$ access the internet for 2-3 hours per day, 9.24\% access the internet 3-4 hours per day, and only $2.52 \%$ access the internet more than 4 hours per day. This data shows that the behavior of students accessing the internet at home is less than 2 hours per day. The causes of the low use of the internet at home are: first, digital culture is still very low, second is the economic condition of students (prioritizing internet packages for smartphones for social media rather than computers), and thirdly not all references, instructions, and student tasks are carried out internet-based. However, the data in Table 2 indicates that internet usage among students is relatively good.

Table 2. Duration of internet usage on campus and homes (hours per day)

\begin{tabular}{lcccccccc}
\hline hours per day & campus & homes & \multicolumn{2}{c}{ campus } & homes & campus & homes & \multicolumn{2}{c}{ campus } & homes \\
& \multicolumn{2}{c}{$<$ hours } & \multicolumn{2}{c}{2 -3 hours } & \multicolumn{2}{c}{$3-4$ hours } & $>4$ hours \\
\hline Number & 21 & 89 & 54 & 16 & 38 & 11 & 6 & 3 \\
Percentage & 17,64 & 74,78 & 45,37 & 13,44 & 31,93 & 9,24 & 5,04 & 2,52 \\
\hline
\end{tabular}

Figure 3 below is a student's acknowledgment of IoET's contribution to the learning process. As many as $52.10 \%$ stated that the internet contributed significantly in supporting the learning process, $26.89 \%$ stated that the contribution of the internet was moderate, $13.44 \%$ stated that the contribution of the internet was low, and $7.56 \%$ stated that the contribution was very low. This data shows that $78.99 \%$ of internet usage has an important and moderate contribution in supporting the learning process. This fact is caused by the positive vision of the use of personal internet about the benefits of campus life. At Universitas Negeri Medan for example, the internet has been used since 2012 for online systems such as registration of prospective students, online examinations, filling in Study Plan Cards, payment of tuition fees and student databases. 


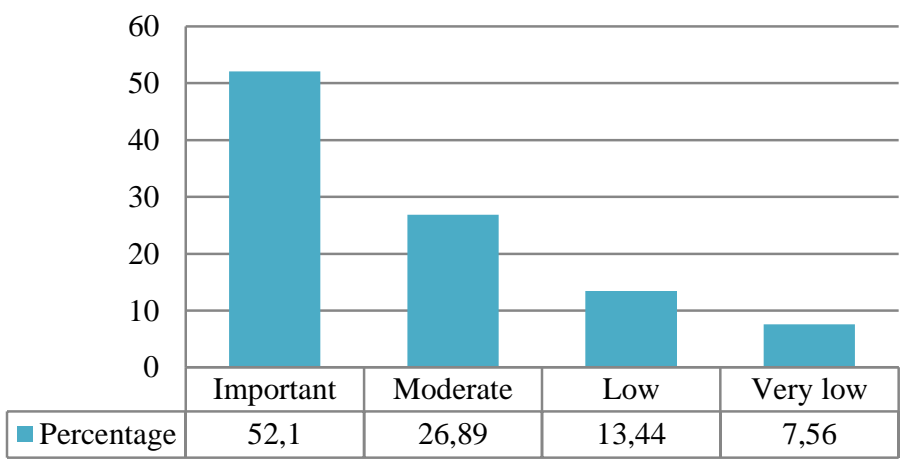

Fig.3. Internet contribution in the learning process

Figure 4 below shows student ownership of computer devices and smartphones in 119 respondents. A total of 104 respondents or $87.39 \%$ had computer devices and smartphones, and 15 respondents or $12.60 \%$ said they only had smartphones without computers. This data shows that all respondents (119 students) or 100\% have smartphones but only 104 or $87.39 \%$ have computers. This means that there are 15 students or $12.60 \%$ who do not have computers. Not having a computer is very much related to the economic conditions of students. The price of smartphones is considered cheaper and portable than computers. Both types of these devices can be used to access the internet even though they have different functions. The computer devices are connected to the internet and are also used to write and do student assignments. Smartphones can be connected to the internet but its function is more to communication and social media.

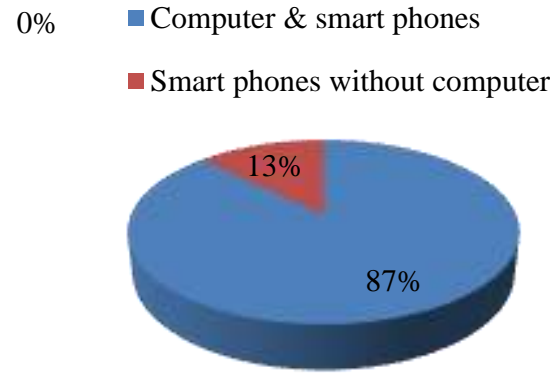

Fig. 4. Internet devices owned by a student

The data in Table 3 below shows the topics and items of the use of the internet for the interests and learning processes in Social Sciences. The tendency of student behavior using the internet is very varied. Data shows that the internet items most frequently used are e-mail and social media 
(100\% each) and internet search engines $83 \%$. Internet topics such as official web browsing (consisting of 4 items) and attending a course in using the internet and its application in education (consisting of 7 items) are still low in use (on average under 50\%). Then, translating references from English, reading sources from various languages, and sharing data via the internet is still very low (2\% each). Likewise, the use of search data by address such as e-news and e-dictionary is still low $(21 \%)$. This reality shows that the web and online sources that are read are sources in Indonesian. This data shows that students' English proficiency is still very low. The data presented in Table 3 is very reasonable when compared to the list of references available in each student task or thesis. This List of References lists more of the official college web or personal blogs that provide articles, journal articles, and theses. While the web of official institutions such as the Archaeological Center, the Center for Preservation of Cultural Values, the Center for Preservation of Cultural Heritage, the Institute of Science, the National Library, the National Archives, and others are still accessed. The websites of independent institutions and organizations such as National Geographic, managers and publishers of journals, e-books, OECD, UNESCO, and others are very rarely accessed.

Table 3. Internet topics and items in the learning process

\begin{tabular}{|c|c|c|}
\hline Topics & Items & Percentage \\
\hline \multirow{3}{*}{$\begin{array}{l}\text { - Search data by index } \\
\text { and addresses for the } \\
\text { learning process }\end{array}$} & $\begin{array}{l}\text { - Internet search engine for Social Sciences teaching } \\
\text { material }\end{array}$ & $83 \%$ \\
\hline & - Access e-dictionary & $7 \%$ \\
\hline & $\begin{array}{l}\text { - Access to internet-based information, news, and } \\
\text { innovations }\end{array}$ & $21 \%$ \\
\hline $\begin{array}{l}\text { - e-Mail for the } \\
\text { learning process }\end{array}$ & - Correspondence and delivery of student task & $100 \%$ \\
\hline \multirow{4}{*}{$\begin{array}{l}\text { - Official web } \\
\text { browsing for the } \\
\text { learning process }\end{array}$} & $\begin{array}{l}\text { - Read and write academic papers from different official } \\
\text { websites }\end{array}$ & $33 \%$ \\
\hline & - In-depth review of internet-based teaching material topics & $6 \%$ \\
\hline & $\begin{array}{l}\text { - Access the website of government agencies and } \\
\text { universities }\end{array}$ & $21 \%$ \\
\hline & $\begin{array}{l}\text { - Access the website of private agencies related to social } \\
\text { science teaching materials }\end{array}$ & $32 \%$ \\
\hline $\begin{array}{l}\text { - Designing web-based } \\
\text { course }\end{array}$ & $\begin{array}{l}\text { - Upload scripts, videos, photos, and images on blogs and } \\
\text { make comments }\end{array}$ & $6 \%$ \\
\hline \multirow{7}{*}{$\begin{array}{l}\text { - Attending a course in } \\
\text { using the internet and } \\
\text { its application in } \\
\text { education }\end{array}$} & $\begin{array}{l}\text { - Read or download photos and images for student } \\
\text { assignments }\end{array}$ & $63 \%$ \\
\hline & $\begin{array}{l}\text { - Read or download or watch videos relevant to teaching } \\
\text { materials }\end{array}$ & $51 \%$ \\
\hline & $\begin{array}{l}\text { - Read or download e-books, e-journals, working papers for } \\
\text { assignments and thesis }\end{array}$ & $42 \%$ \\
\hline & - Translate English references with internet devices & $2 \%$ \\
\hline & - Read sources from various languages & $2 \%$ \\
\hline & - Share data via the internet & $2 \%$ \\
\hline & - Access e-learning system & $37 \%$ \\
\hline
\end{tabular}


- Social media for educational communication
- Interconnection through messenger, MSN, Facebook, Twitter and WhatApps for academic and homework purposes

Table 4 below shows the other users of the internet through computers and smartphones. Data shows that social media (100\%), e-music and song (95.79\%), e-games $(78.15 \%)$ and e-commerce $(73.10 \%)$ are the most common uses of the internet. Also, there were $52.10 \%$ used the internet for online gambling and $35.29 \%$ was used to watch the e-cinema. The data presented in Table 4 makes perfect sense when utilizing free time on campus. Student behavior in the cafeteria, outside the classroom or even in class when the lecturer is not present tends to use the internet that is not related to academic purposes. This indication shows that the ability to learn independently, collectively and collaboratively utilizing the internet is still low. The data in Table 4 compared to Table 3 above concludes that students use the internet more for academic purposes.

Table 4. Other usages of the Internet through computers and smartphones

\begin{tabular}{ccc}
\hline Other uses of the internet & Total & Percentage \\
\hline e-games & 93 & $78,15 \%$ \\
e-cinema & 42 & $35,29 \%$ \\
e-music and song & 114 & $95,79 \%$ \\
e-gambling & 62 & $52,10 \%$ \\
e-commerce (online shops) & 87 & $73,10 \%$ \\
social media & 119 & $100 \%$ \\
\hline
\end{tabular}

As stated at the beginning of this paper that the internet has a major impact on the improvement and improvement of the quality of education. The results of the study's correlation test show that IoET contributed $12.1 \%$ to the increase in student academic purposes. This contribution is still relatively low. In the current 4IR era, especially with e-learning models, for example, the contribution should increase even higher. However, several factors that contributed to the low contribution of IoET to student academic purposes were identified as follows: (1) IoET namely digital literacy has not yet become a necessity or habit. Teaching material still relies on printed references (books and journal articles). Therefore, the efforts of students to access internetbased teaching materials are still limited, (2) IoET is related to digital fluency, namely proficiency in using technology to access various sources (e-books, e-journals, e-dictionaries, official websites, e-learning tutorials) and others. This limitation makes it relatively difficult for students to access and use the internet, (3) low English proficiency. The results of this study indicate that the ability of English-speaking students is still very low (only 8 out of 119 respondents or $6.72 \%$.

The low English proficiency has an impact on the use of the internet only focused on Indonesian, (4) not all lecturers use internet devices in the learning process such as access to references, e-learning systems, tutorials and instructions as well as student assignments. Until this research was completed, only 3 lecturers used the internet, especially in e-learning and thesis consulting, (5) limitations of campus WiFi. Until now, not all classes have access to the internet. WiFi is only available in certain rooms and at this location students access the campus internet, and (6) it is likely related to the family's economic conditions. Students tend to utilize campus 
internet and not at home. Even if the internet package is owned by students, then the tendency is used for the benefit of smartphones for social media.

The adverse impact of IoET that can be observed to date is plagiarism. Not a few, both student assignments and thesis are reproductions of the same theme from different campuses. Ironically, during this study, the thesis was copied and pasted from another campus and only the location of the study was changed. It turns out, for some students, the availability of references and online materials (e-books, e-journals, and websites) have an impact on plagiarism, reduplication, and falsification. Not infrequently, student thesis is the result of plagiarism from various regions and only deletes the research location. However, some lecturers (such as the author of this article) already have a plagiarism detection tool. The tolerance limit for similarity of scientific work (both student assignments and thesis) is $30 \%$. Beyond this limit will be rejected. However, not all lecturers have similarity detection devices. Also, departments and faculties do not have plagiarism detection devices. This fact makes it difficult to detect plagiarism among students.

The hypothesis testing study concluded that IoET contributed positively and significantly in the learning process to improve student academic purposes. Its contribution reached $12.1 \%$. This correlation coefficient indicates that the contribution of IoET to student academic purposes is still low. However, if IoET is maximized as much as possible, for example up to $30 \%$, the effect on student academic purposes will increase to $42.1 \%$. Therefore, efforts are needed to activate the awareness of students using the internet for their learning purposes, such as (1) delivery of teaching materials in the form of e-books, e-journals, videos, and websites. Through this effort, students have an awareness of the significance of the internet which provides a variety of sources in various languages.

In this case, educators must have a high commitment to changes in the field of education according to 4IR, (2) as far as possible deliver tutorials, instructions, evaluations, monitoring, and internet-based consultation. Computer devices and smartphones are connected to the internet so they can access learning wherever and whenever. Students must have an awareness of their position so that the internet is more widely used to support the learning process on campus or at home, (3) direct students to access diverse language sources (especially English) and suggest translating them online, and (4) utilize e-tools learning or blended learning in the learning process. Based on this description, the use of IoET in Social Sciences is shown in Figure 5 below, namely: 


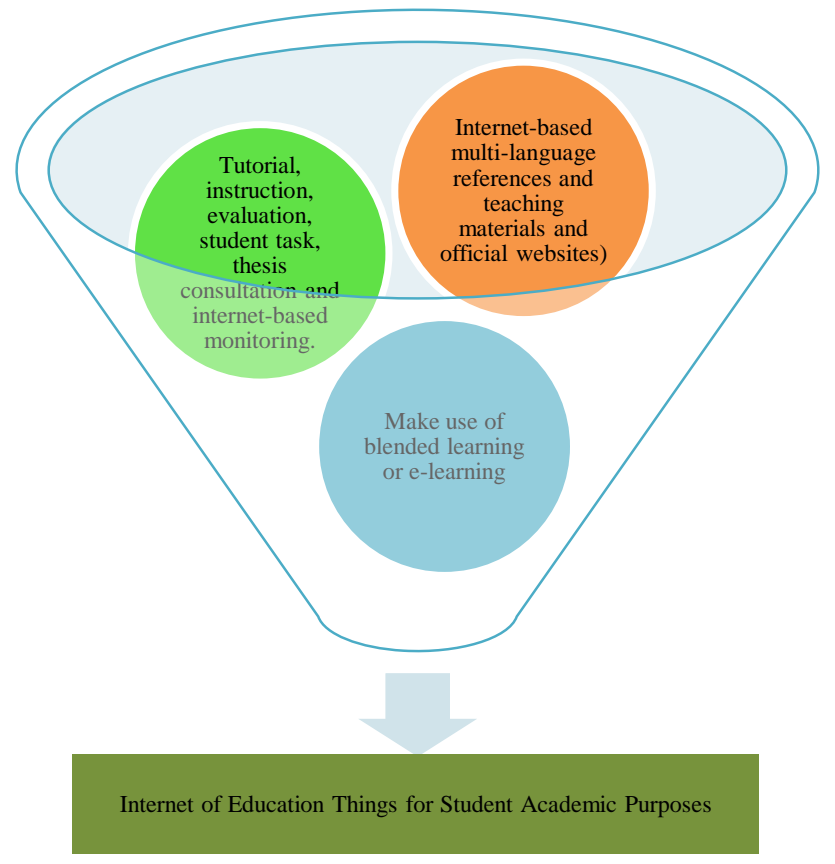

Fig. 5. Efforts to use IoET in Social Sciences in the learning process

This novel mentions that IoET contributes positively and significantly to students' academic purposes. However, IoET has not created a culture of digital literacy for the learning process to improve student academic purposes. In other words, although students often use the internet the tendency is not for student academic purposes but rather for other uses. For example, social media, e-music, and song, e-games, e-commerce, e-gambling, and e-cinema, etc. This reality is very closely related to digital culture that has not grown well among students. To foster a digital culture in the learning process, IoET must be a standardized reference. The paradigm of the internet must be directed at its function namely IoET.

Internet support in the learning process is a new literacy in the 4IR era. This technology enables searching and finding various information and data in various languages that can be processed into teaching material to create new knowledge. In the 4IR era, educators were advised to have a high commitment to educational changes that occurred in the $21^{\text {st }}$ Century. Educators must have the ability to access resources and direct students to mastering the source of teaching materials in various languages. Educators must be able to create a more personal learning atmosphere in schools, homes, and communities. Educators must be able to engage students in contextual learning according to the needs of the nation and society. In other words, the effect of educators on IoET is the ability of knowledge to solve problems besides the acquisition of global competencies and skills in the $21^{\text {st }}$ Century. 
Regarding this problem, the contribution of Social Sciences is not only theoretical but must have an impact on problem-solving. In this case, every student must know any problems in society and try to give a solution. Therefore, teaching material must be directed at creating casuistic-based problem-solving. References such as e-books and e-journals or videos, streaming, documentaries, and movies are highly recommended for access. Cases that illustrate reality and social phenomena such as sexual harassment, crime, divorce, war, poverty, anarchist demonstrations, traffic jams, garbage, climate change, global warming, abortion, injustice as much as possible are accessed by students and explain. Based on the description above, IoET's contribution to student academic purposes emphasizes the benefits of digital technology as critical literacy, creative literacy, and network literacy. All three are useful for developing effectiveness and ethics for creating and sharing knowledge collaboratively.

The internet has great potential for improving the quality of education [28]-[30]. The internet has positive implications for teachers and lecturers [29]. For students, the internet allows finding information and leading it to think critically and creatively, collaboratively and cooperatively in solving problems [31]. Students must be able to manage independent learning, access many sources, communicate and discuss with many friends and try to offer solutions for problems faced in society, students must have global competence and skills in the 21 st century and be able to offer innovation, creativity, and problem-solving. In this case, IoET has a contribution that is the availability of various sources in various languages, so what is needed is the persistence of students gathering all sources and creates new knowledge that is useful for science and society.

The IoET has a pedagogical impact and becomes a new literacy that is very important for the ability to use online and offline databases through web search engines in cyberspace, namely organizing, structuring and evaluating the information space [32]. Ultimately, the internet is a new literacy in the era of digital technology namely (i) critical literacy, namely a deep understanding of contextual situations that are informed through the internet, (ii) creative literacy, that is, the ability to experiment with the internet to create and absorb information, and (iii) literacy network, ability and the impulse to effectively and ethically manipulate a range of Internet technologies to communicate and collaboratively construct and share knowledge [3].

\section{Conclusion}

The hypothesis testing concluded that IoET contributed positively and significantly to the learning process to improve student academic purposes. However, IoET's contribution to the learning process is still in the low category. This conclusion confirms and accepts the theory used that the breakthrough $4 \mathrm{IR}$ or digital technology in the $21^{\text {st }}$ Century contributed to the educational process. In this case, 4IR creates a more personal experience and learning process, accessing various references and teaching materials from various sources. Interconnection and virtualization of education and learning foster digital literacy and digital fluency in the $21^{\text {st }}$ Century. Digital literacy has an impact on critical literacy, creative literacy and networking literacy that students have. With this literacy, learning Social Sciences in the 4IR era was able to answer social life in the $21^{\text {st }}$ Century. 
The findings of this study state that IoET has not created a culture of digital literacy for the learning process to improve student academic purposes. Although students often use the internet the tendency is not for student academic purposes but rather for other uses. This fact is very closely related to digital culture that has not grown well among students. Furthermore, to foster a digital culture in the learning process, IoET must be a standardized reference. The paradigm of the internet must be directed at the function and usefulness of IoET in education and learning processes. Therefore, both educators and students must have a high commitment to the 4IR contribution in the 21 st Century that created this digital technology.

\section{References}

[1] L. McRae, The Internet of Things (IoT): Education and Technology: The relationship between education and technology for a student with disabilities. Curtin: Curtin University, 2018.

[2] K. Schwab, The Fourth Industrial Revolution by Klaus Schwab. London: Penguins Books., 2017.

[3] J. Burgess, "Blogging to learn, learning to blog," in Uses of Blogs, A. Bruns, Ed. New York: Peter Lang, 2006, pp. 104-114.

[4] R. Groscurth, Future-ready leaderships: Strategies for the fourth industrial revolution. Santa Barbara, California: ABC-CLIO., 2018.

[5] E. Fleisch, "What is the Internet of Things?: An Economic Perspective.," Zurich, BIZAPP-053, 2010.

[6] ITU, "ITU Internet Reports 2005: The Internet of Things-Executive Summary.," The Internet of Things-Executive Summary, $2005 . \quad$ AOnline]. https://www.itu.int/osg/spu/publications/internetofthings/. [Accessed: 21-Jul-2019].

[7] C. Dede, The role of digital technologies in deeper learning. Students at the Center: Deeper Learning Research Series. Boston, MA: Jobs for the Future., 2014.

[8] W. Gleason, Higher education in the era of the fourth industrial revolution. Singapore: Palgrave Macmillan., 2018.

[9] M. Prensky, "Digital Natives, Digital Immigrants.," Horiz., vol. 9, no. 5, pp. 1-6, 2001.

[10] N. Dogruera, "The use of the internet for educational purposes.," in Procedia-Social and Behavioral Sciences 28, 2011, pp. 606-611.

[11] B. Garner, Blended Learning: Theoretical Foundations. Indiana Wesleyan University: The Brief Report Series from the Center for Learning and Innovation. Indiana: Indiana Wesleyan University, 2017.

[12] M. B. Abbasi, "Predictable Influence of IoT (Internet of Things) in the Higher Education.," Int. J. Inf. Educ. Technol., vol. 7, no. 12, pp. 914-920, 2017.

[13] D. Geladze, "Using the Internet and Computer Technologies in Learning/Teaching Process.," $J$. Educ. Pract., vol. 6, no. 2, pp. 67-70, 2015.

[14] D. Thomas, A new culture of learning: Cultivating the imagination for a world of constant change. Charleston, SC: CreateSpace., 2011.

[15] ITU, "Internet of things global standards initiative.," Internet of things global standards initiative, 2012. [Online]. Available: http://www.itu.int/en/ITU-T/gsi/iot/Pages/default.aspx. [Accessed: 21Jul-2019].

[16] T. Mitew, "Do objects dream of an internet of things? The Fibreculture Journal: Retrieved from," Digital Media + Networks + Transdisciplinary Critique, 2014. [Online]. Available: http://fibreculturejournal.org/wp-content/pdfs/FCJ-168Teodor Mitew.pdf. [Accessed: 26-Jul-2019].

[17] R. Parashar, "A survey: The internet of things," Int. J. Tech. Res. Appl., vol. 4, no. 3, pp. 251-257, 2016.

[18] K. Asthon, “That 'Internet of Things'.," RFID Journal., 2009. [Online]. Available: 
http://www.rfidjournal.com/articles/view?4986. [Accessed: 12-Jun-2019].

[19] ISOC, "The internet of things (IoT): An overview.," Understanding the issues and challenges of a more connected world., $2015 . \quad$ Anline]. https://www.internetsociety.org/sites/default/files/ISOC-IoT-Overvie w-20151014_0.pdf. October. [Accessed: 04-Jun-2019].

[20] J. Wiliams, "Internet of things: Science fiction or business fact?" Harvard, 2014.

[21] I. Asseo, "the Internet of things: Riding the Wave in Higher Education," Educ. Rev. Mag., vol. 51, no. 4, pp. 10-33, 2016.

[22] C. Benson, "The Internet of Things: IoT System, and Higher Education.," Educ. Rev. Mag., vol. 51, no. 4, pp. 34-43, 2016.

[23] M. Selinger, "Education and the internet of everything: How ubiquitous connectedness can help transform pedagogy," Cisco Consulting Service and Cisco EMEAR Education Team, 2013.

[24] H. Park, "Academic Internet Use: Issues and Lessons in e-Research.," 2009, p. 5.

[25] K. S. Taber, "The Use of Cronbach's Alpha When Developing and Reporting Research Instruments in Science Education,” Res. Sci. Educ., vol. 48, no. 6, pp. 1273-1296, 2017.

[26] R. Simard, “Computing the Two-Sided Kolmogorov-Smirnov Distribution,” J. Stat. Softw., vol. 39, no. 11 , pp. 1-18, 2011.

[27] J. Benesty, "Pearson Correlation Coefficient," in Noise Reduction in Speech Processing, 2nd ed., Heidelberg: Springer, 2009, p. 56.

[28] M. Ciglaric, "The use of Internet technologies for teaching purposes," Eur. J. Eng. Educ., vol. 23, no. 4, pp. 497-503., 1998.

[29] S. Charp, "The millennium classroom," T.H.E. J., vol. 27, no. 10, pp. 10-12, 2000.

[30] D. Laurilard, "Learning through collaborative computer simulation," Br. J. Educ. Technol., vol. 23, no. 3, pp. 164-171, 1992.

[31] O. E. Dryli, "Energizing the classroom curriculum through telecommunications"., vol. 16, no. 4, pp. 57-70.," Technol. Learn., vol. 16, no. 4, pp. 57-70, 2016.

[32] M. Nentwich, Cyberscience: Research in the age of the Internet. Vienna: Austrian Academy of Science Press., 2003. 